\title{
Use of rice husk ash to produce alternative sodium silicate for geopolymerization reactions
}

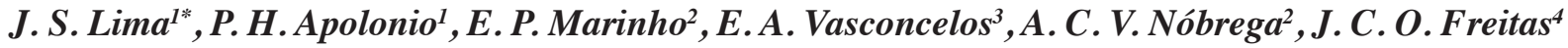 \\ ${ }^{1}$ Universidade Federal de Pernambuco, Programa de Pós-graduação em Engenharia Civil, \\ Centro de Tecnologia e Geociências, Recife, PE, Brazil \\ ${ }^{2}$ Universidade Federal de Pernambuco, Programa de Pós-graduação em Engenharia Civil e Ambiental, \\ Campus Acadêmico do Agreste, Caruaru, PE, Brazil \\ ${ }^{3}$ Universidade Federal de Pernambuco, Núcleo de Tecnologia, Campus Acadêmico do Agreste, Caruaru, PE, Brazil \\ ${ }^{4}$ Universidade Federal do Rio Grande do Norte, Departamento de Química, Natal, RN, Brazil
}

\begin{abstract}
This study investigated the feasibility of synthesizing sodium silicate from rice husk ash (RHA) and its application to produce geopolymers. Samples were prepared at different $\mathrm{SiO}_{2} / \mathrm{Al}_{2} \mathrm{O}_{3}$ molar ratios $(3.0,3.5$, and 4.0) for both sodium silicates (commercial and from RHA). They were underwater cured at $60{ }^{\circ} \mathrm{C}$ for $1 \mathrm{~h}$ and then at room temperature $\left(25^{\circ} \mathrm{C}\right.$ in the air $)$ until the time of the tests ( 7 and 28 days). The results showed that the compressive strength significantly increased along with the $\mathrm{SiO}_{2} / \mathrm{Al}_{2} \mathrm{O}_{3}$ ratio for both silicates. Geopolymers produced with sodium silicate from RHA showed higher compressive strengths for most studied samples. The highest compressive strength $(6.33 \pm 0.23 \mathrm{MPa})$ was obtained for samples with $\mathrm{SiO}_{2} / \mathrm{Al}_{2} \mathrm{O}_{3}$ ratio of 4.0 at 7 days, representing a $40 \%$ increase in average values compared to commercial sodium silicate under the same conditions. XRD data and FTIR spectrum confirmed that it was possible to synthesize a geopolymer with sodium silicate using RHA.
\end{abstract}

Keywords: geopolymer, rice husk ash, waterglass, $\mathrm{SiO}_{2} / \mathrm{Al}_{2} \mathrm{O}_{3}$ ratio, Fourier-transform infrared (FTIR) spectroscopy.

\section{INTRODUCTION}

Geopolymers are a promising class of materials produced by the polymerization of silicon, aluminum, and oxygen species, forming an amorphous three-dimensional framework structure [1-4]. They are formed by the reaction between a precursor and an activator solution at a strong alkaline medium [5]. Any source of amorphous alumina and silica is a possible source of geopolymer precursor species [6]. In addition, an activator solution is any solution that provides a strong alkaline medium that is necessary to occur the reaction. Also, the dissolution of $\mathrm{Si}$ and $\mathrm{Al}$ species is very dependent on alkali and its concentration. Adequate dissolution generates a geopolymer with high strength [7]. The most popular alkali activators are sodium hydroxide, sodium silicate, sodium aluminate, sodium carbonate, and potassium hydroxide [8]. Further, the activator solution containing soluble silicates promotes a faster rate of reaction than solutions with only alkaline hydroxides [9].

Studies have shown that geopolymers are potential candidates to replace Portland cement due to the fact that they can enhance mechanical properties and durability aspects when compared to standard Portland cement blends. The production of geopolymeric materials also generates lower carbon dioxide emission and reuse of industrial byproducts

*jofresl@gmail.com

Dhttps://orcid.org/0000-0001-6097-6230
$[10,11]$. A decrease of $50 \%$ in $\mathrm{CO}_{2}$ emission compared to ordinary Portland cement blends is cited [12]. Nonetheless, the main environmental impacts of geopolymers depend on the raw materials used in the production of reagents. The synthesis of the sodium silicate solution (commercial waterglass) $[12,13]$ is particularly problematic. Commercial waterglass is produced from sodium carbonate $\left(\mathrm{Na}_{2} \mathrm{CO}_{3}\right)$ and quartz $\left(\mathrm{SiO}_{2}\right)$ calcined between 1400 and $1500^{\circ} \mathrm{C}$, generating $1.5 \mathrm{~kg}$ of $\mathrm{CO}_{2}$ per $\mathrm{kg}$ of waterglass $[13,14]$. This explains why alternative materials have been studied as potential substitutes to this chemical reagent. Waterglass produced from waste glass [15], bamboo leaves [16], silica fume [17], nanosilica [18], and rice husk ash [13-15] are examples of alternative sources of silica to produce alternative waterglass. Rice husk ash (RHA) is one of the most promising materials, not only for its high amount of silica but also on account of the high global rice production [19]. RHA has been shown as a viable alternative to commercial waterglass in order to produce sustainable geopolymers [13-15, 20-23].

Besides, the geopolymerization reactions are influenced by various factors $[1,3,7,24-30]$ : a) concentration of alkaline solution [31-33]; b) alkali metal cation in alkaline solution [31-33]; c) stirring time, intensity, and speed; d) leaching period (associated with leaching of both $\mathrm{Al}$ and $\mathrm{Si}$ in alkaline solution [31]); e) structure and composition of aluminosilicate material [31]; f) alkalinity [31, 32]; g) curing temperature [34, 35]; h) air circulation [34]; i) $\mathrm{SiO}_{2} / \mathrm{Al}_{2} \mathrm{O}_{3}$ molar ratio [36-38]; j) $\mathrm{SiO}_{2} / \mathrm{M}_{2} \mathrm{O}$ molar ratio (where $\mathrm{M}$ is an alkaline ion such as $\mathrm{Na}$ or K) [33]; and k) solid/liquid ratio [6]. Therefore, the effective 
$\mathrm{SiO}_{2} / \mathrm{Al}_{2} \mathrm{O}_{3}$ ratio greatly affects several geopolymerization reaction steps. Hence, the final geopolymer application and its properties are related to the $\mathrm{SiO}_{2} / \mathrm{Al}_{2} \mathrm{O}_{3}$ ratio [7]. Few studies are focused on the relationship between alternative silicates and geopolymerization reactions, especially using the Fourier-transform infrared (FTIR) spectroscopy. The FTIR spectroscopy is an easy way to understand the formation of geopolymer and its relation to strength. In short, the understanding of geopolymer reaction and the replacement of commercial silicate can help researchers to develop new eco-friendly building techniques. In this scenario, this paper aimed to investigate the feasibility of synthesizing sodium silicate from rice husk ash and its application as an activator to produce metakaolin-based geopolymers. The influence of $\mathrm{SiO}_{2} / \mathrm{Al}_{2} \mathrm{O}_{3}$ molar ratio on compressive strength and microstructural characteristics of these geopolymers was also investigated.

\section{MATERIALS AND METHODS}

Raw materials: the following raw materials were used: metakaolin (MK, Metacaulim do Brasil) as an aluminosilicate material, also called geopolymeric precursor; rice husk ash (RHA, Silroz 325, Marina Tecnologia) and sodium silicate solution (R3342, Diatom) as alternative and commercial sources of silica, respectively; $\mathrm{NaOH}$ (Química Moderna, purity $>97 \%$ ) as alkali activator; and distilled water. $M K$ and RHA: the chemical compositions of $\mathrm{MK}$ and RHA were obtained by semiquantitative analysis using an X-ray fluorescence spectrometer (EDX-720/800HS, Shimadzu). The chemical composition data, loss on ignition, humidity, specific gravity, and specific surface area (Blaine value) are presented in Table I. The X-ray diffraction (XRD) patterns concerning the mineralogical characterization of MK and RHA are presented in Fig. 1. The XRD analyses

Table I - Physico-chemical characteristics of the raw materials used (metakaolin, MK, and rice husk ash, RHA).

\begin{tabular}{ccc}
\hline Characteristic & $\mathrm{MK}$ & $\mathrm{RHA}$ \\
\hline $\mathrm{SiO}_{2}(\%)$ & 53.06 & 80.00 \\
$\mathrm{Al}_{2} \mathrm{O}_{3}(\%)$ & 36.50 & - \\
$\mathrm{K}_{2} \mathrm{O}(\%)$ & 1.36 & 3.44 \\
$\mathrm{CaO}(\%)$ & 0.86 & 1.14 \\
$\mathrm{MgO}(\%)$ & 0.27 & - \\
$\mathrm{Fe}_{2} \mathrm{O}_{3}(\%)$ & 4.42 & 0.82 \\
$\mathrm{MnO}^{(\%)}$ & - & 2.85 \\
$\mathrm{SO}(\%)$ & - & 1.34 \\
Others $(\%)$ & 1.37 & 0.82 \\
$\mathrm{LOI}(\%)$ & 2.15 & 9.59 \\
$\mathrm{Humidity}(\%)$ & 1.18 & 2.41 \\
Specific gravity $\left(\mathrm{g} / \mathrm{cm}^{3}\right)$ & 2.53 & 2.16 \\
Specific surface area $\left(\mathrm{m}^{2} / \mathrm{kg}\right)$ & 1242.3 & 1671.9 \\
\hline
\end{tabular}
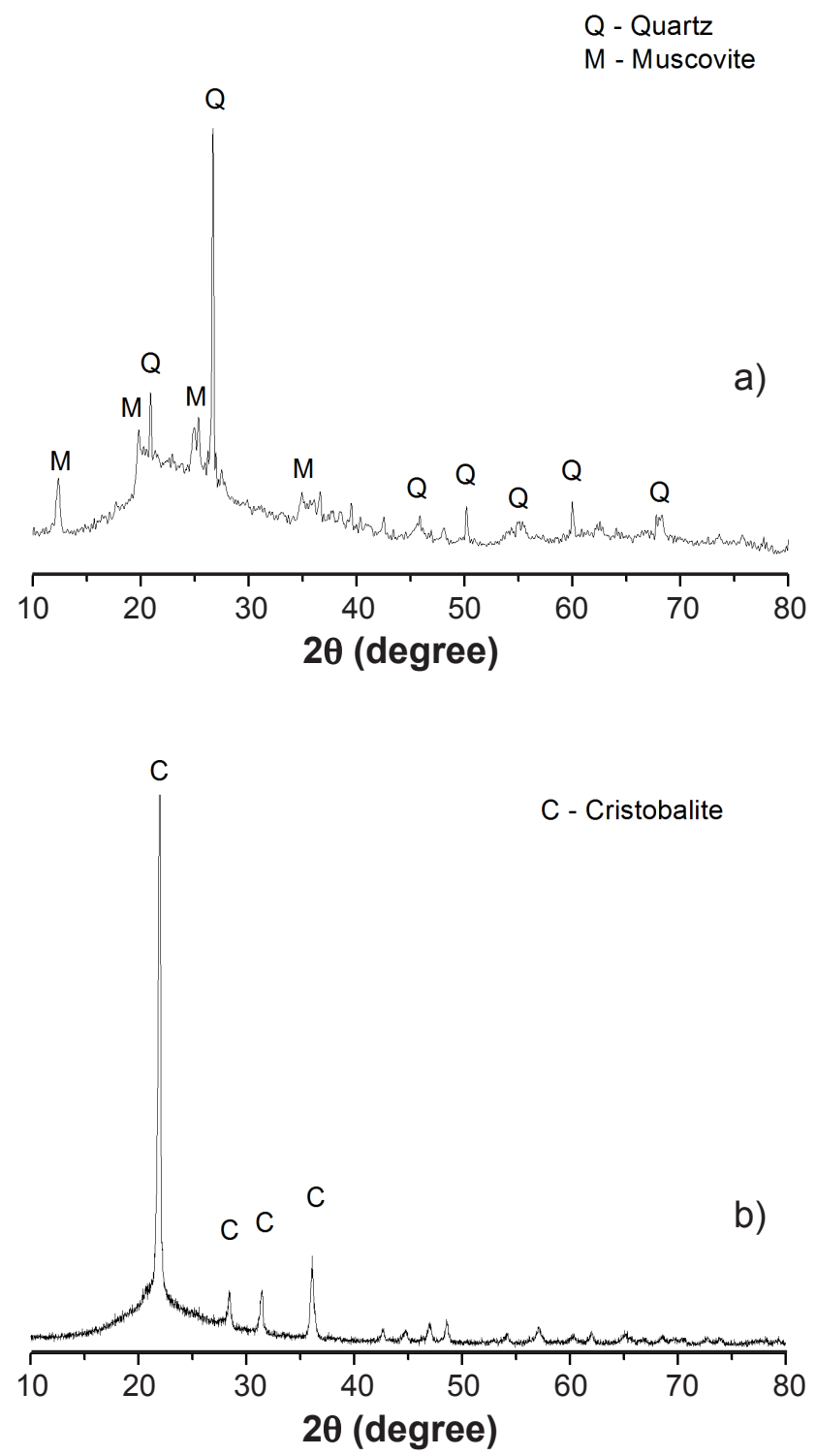

Figure 1: X-ray diffraction patterns of: a) metakaolin (MK); and b) rice husk ash (RHA)

were performed with $\mathrm{CuK} \alpha$ radiation $(40 \mathrm{kV} / 30 \mathrm{~mA})$, a goniometer speed of $0.02^{\circ} 2 \theta / \mathrm{step}$ with $1.0 \mathrm{~s} / \mathrm{step}$ count time in the range of $10^{\circ}$ to $80^{\circ} 2 \theta$. The presence of amorphous halo indicated that the MK (Fig. 1a) used in the production of geopolymers was an amorphous material; there was no presence of kaolinite, but quartz and muscovite were identified $[39,40]$. The amorphous halo was also identified in RHA sample (Fig. 1b); the presence of cristobalite [21, 41] indicated that the calcining of rice husk ash was carried out at a high temperature for a long time [42].

Silicates. Production of alternative silicate from RHA: the production process of the alternative silicate consisted of mixing RHA, sodium hydroxide, and distilled water in a reflux system for $2 \mathrm{~h}$ [20] at $90{ }^{\circ} \mathrm{C}$ [43]. A rotary vacuum evaporator coupled with a thermal bath (TE-211, Tecnal) was used to keep the temperature constant with heating oil and to maintain the rotation at $2 \mathrm{rpm}$. Note that the final solution was not filtered. Alternative silicate from RHA 
versus commercial silicate: the chemical compositions of the alternative silicate from rice husk ash and the commercial sodium silicate (manufacturer's data) are presented in Table II, and the results of dynamic viscosity, specific density, and $\mathrm{pH}$ are shown in Table III. The silicate from the rice husk ash (SRHA) was formulated to maintain the molar ratio of $\mathrm{SiO}_{2} / \mathrm{Na}_{2} \mathrm{O}$ and $\mathrm{H}_{2} \mathrm{O} / \mathrm{Na}_{2} \mathrm{O}$ equal to the commercial sodium silicate (SS). As expected, the chemical composition of the SRHA was according to the compositions of the starting materials (Table II). The silicate produced from rice husk ash presented a similar dissolution capacity of silica and alumina when compared to the commercial sodium silicate $\left(\mathrm{pH}_{\mathrm{SRHA}}=12.60\right.$, similar to $\left.\mathrm{pH}_{\mathrm{SS}}=12.66\right)$. The presence of organic matter in the SRHA, confirmed by the results of loss on ignition (Table II), increased the density by $7.7 \%$. In terms of viscosity, the SRHA had a dynamic viscosity different from the commercial sodium silicate used (SS). However, other commercial silicates exhibit dynamic viscosity between 150 and $300 \mathrm{cP}$ [44], similar to SRHA.

Table II - Chemical compositions of the silicates (commercial sodium silicate, SS, and silicate from RHA, SRHA).

\begin{tabular}{ccc}
\hline Oxide & $\mathrm{SS}$ & SRHA \\
\hline $\mathrm{SiO}_{2}(\%)$ & 30.00 & 29.03 \\
$\mathrm{Na}_{2} \mathrm{O}(\%)$ & 9.00 & 8.71 \\
$\mathrm{~K}_{2} \mathrm{O}(\%)$ & - & 1.25 \\
$\mathrm{Fe}_{2} \mathrm{O}_{3}(\%)$ & - & 0.30 \\
$\mathrm{H}_{2} \mathrm{O}(\%)$ & 61.00 & 59.02 \\
Others $(\%)$ & - & 1.70 \\
LOI (\%) & - & 3.48 \\
\hline
\end{tabular}

Table III - Characterization results of silicates.

\begin{tabular}{ccc}
\hline Property & SS & SRHA \\
\hline Density $(\mathrm{g} / \mathrm{mL})$ & 1.56 & 1.68 \\
Density $\left({ }^{\circ} \mathrm{Be}\right)$ & 52.17 & 58.56 \\
$\mathrm{pH}$ & 12.66 & 12.60 \\
Viscosity $(\mathrm{cP})$ & 796 & 196 \\
\hline
\end{tabular}

SS: commercial sodium silicate; SRHA: alternative silicate from rice hush ash.

Table IV - Formulation data of geopolymers.

\begin{tabular}{ccccc}
\hline ID & $\begin{array}{c}\mathrm{SiO}_{2} / \\
\mathrm{Al}_{2} \mathrm{O}_{3}\end{array}$ & $\begin{array}{c}\text { Sodium } \\
\text { silicate }\end{array}$ & $\begin{array}{c}\mathrm{Na}_{2} \mathrm{O} / \\
\mathrm{Al}_{2} \mathrm{O}_{3}\end{array}$ & $\begin{array}{c}\mathrm{H}_{2} \mathrm{O} / \\
\mathrm{Na}_{2} \mathrm{O}\end{array}$ \\
\hline $3.0 \mathrm{SS}$ & 3.0 & $\mathrm{SS}$ & 1.0 & 15.0 \\
$3.5 \mathrm{SS}$ & 3.5 & $\mathrm{SS}$ & 1.0 & 15.0 \\
4.0SS & 4.0 & $\mathrm{SS}$ & 1.0 & 15.0 \\
3.0SRHA & 3.0 & SRHA & 1.0 & 15.0 \\
3.5SRHA & 3.5 & SRHA & 1.0 & 15.0 \\
4.0SRHA & 4.0 & SRHA & 1.0 & 15.0 \\
\hline
\end{tabular}

Geopolymer synthesis: metakaolin was used as an aluminosilicate material (precursor) in the production of geopolymeric pastes. As an activator solution, the sodium hydroxide along with silicon sources SRHA and SS were used. Both $\mathrm{NaOH}$ and SRHA solutions were prepared $24 \mathrm{~h}$ before the mixing of the pastes. The geopolymers produced were identified according to Table IV. No water was added. The samples were cured in two stages: 1) immersed in water inside an industrial oven at $60{ }^{\circ} \mathrm{C}$ (constant, controlled temperature) for $1 \mathrm{~h}$; and 2) in air, at controlled room temperature of $25^{\circ} \mathrm{C}$ from the second hour until the tests were performed. Compressive strength tests at 7 and 28 days were carried out. The samples cured at 28 days were crushed, then passed through a $75 \mu \mathrm{m}$ sieve (No. 200) for XRD and FTIR measurements. The XRD analyses were performed with the same test conditions described for the raw materials. In addition, for the FTIR analysis, the powder samples were mixed with $\mathrm{KBr}$ and compressed into pellets, and then analyzed in the spectral range from 4000 to $400 \mathrm{~cm}^{-1}$.

\section{RESULTS AND DISCUSSION}

XRD analysis of geopolymers: Fig. 2 presents the diffractograms of the studied geopolymers. All samples geopolymerized as shown by the presence of amorphous halo, indicating that the alternative silicate based on rice husk ash was suitable for the production of geopolymers $[13-15,20-23]$. The alteration of the broad band at $15-35^{\circ} 2 \theta$ in the metakaolin to $20-40^{\circ} 2 \theta$ in the geopolymeric pastes indicated the formation of an amorphous gel, characteristic of a satisfactory geopolymerization [45-49]. Two factors were responsible for the formation of the amorphous halo in geopolymers [48]: i) formation of a large amount of amorphous gel due to activation of the metakaolin, and ii) change in the nature of the amorphous gel due to the inclusion of $\mathrm{Na}$ and the alteration of the hydration state of the aluminosilicate network. The geopolymeric pastes did not present distinct crystalline phases from those observed

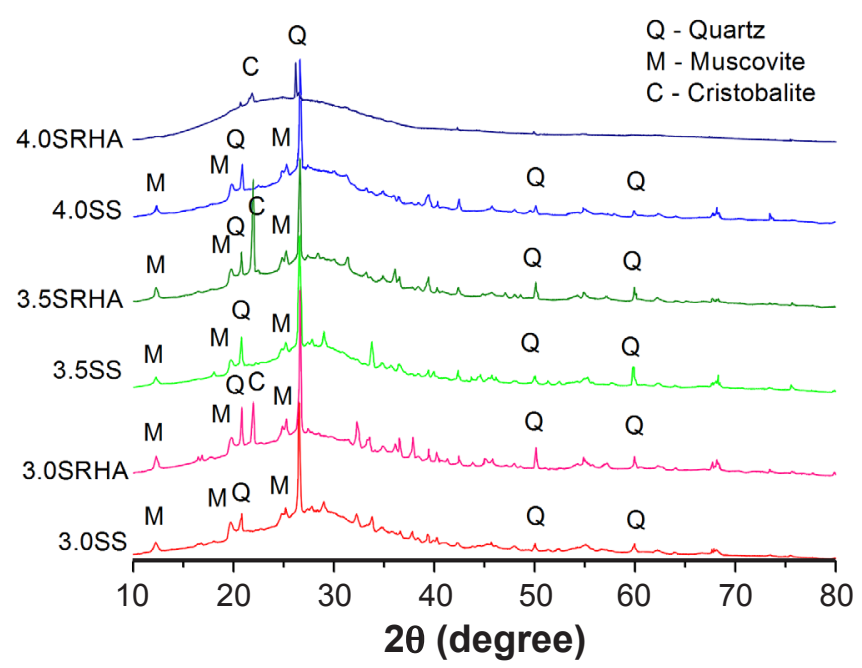

Figure 2: X-ray diffraction patterns of geopolymers. 
in the raw materials (Fig. 1). However, when comparing to the precursors, a reduction in crystalline peaks was identified, indicating that some of the crystalline phases were consumed in the geopolymerization reactions. The intensity of the quartz and muscovite peaks presented a decrease in all geopolymers. A similar phenomenon was observed for the cristobalite peak in the geopolymers molded with SRHA (3.0 SRHA, 3.5 SRHA, and 4.0 SRHA). The same behavior was identified in other studies [47-51]. When comparing different geopolymers molded with the same silicate (SS or SRHA), it was observed an increase of the sample amorphization with the increase of $\mathrm{SiO}_{2} / \mathrm{Al}_{2} \mathrm{O}_{3}$ molar ratio. The addition of soluble silicate, through activator solutions in geopolymers, increased the disorder of the generated material without modifying the reaction mechanism [52]. A reduction in the ordering level was observed with the increase of the $\mathrm{SiO}_{2} / \mathrm{Al}_{2} \mathrm{O}_{3}$ molar ratio.

FTIR of geopolymers, MK, and RHA: Fig. 3 presents the infrared absorption spectra for MK and RHA, as well as for geopolymers produced with SS and SRHA. Raw materials: for MK, the absorption bands indicated the presence of amorphous silica at $1035 \mathrm{~cm}^{-1}$ ( $\mathrm{Si}-\mathrm{O}-\mathrm{Si}$ asymmetric stretching), $796 \mathrm{~cm}^{-1}$ (Si-O-Si symmetric stretching), and $472 \mathrm{~cm}^{-1}$ (Si-O-Si and O-Si-O bending). Also, the presence of amorphous alumina was assigned at the wavenumbers of $1035 \mathrm{~cm}^{-1}$ (Al-O-Si asymmetric stretching) and $913 \mathrm{~cm}^{-1}$ ( $\mathrm{OH}^{-}$bending band; $\mathrm{OH}$ groups bonded to $\mathrm{Al}$ ), while the band at $3620 \mathrm{~cm}^{-1}$ was associated to the $\mathrm{OH}$ group deformation $(\mathrm{O}-\mathrm{H}$ vibrations) $[14,53,54]$. The peaks at 913 and $796 \mathrm{~cm}^{-1}$ on the FTIR spectrum of MK were referred to -OH bond and Si-OSi symmetric stretching, respectively, may also be related to quartz, according to the data obtained by the X-ray diffraction analysis (Fig. 1a) [14, 53-55]. For the RHA, the absorption bands indicated the presence of amorphous silicon at wavenumbers of $1090 \mathrm{~cm}^{-1}$ (Si-O-Si asymmetric stretching), $798 \mathrm{~cm}^{-1}$ (Si-O-Si symmetric stretching), $621 \mathrm{~cm}^{-1}$ (Si-O-Si symmetric stretching), and $465 \mathrm{~cm}^{-1}$ (Si-O-Si and O-Si-O bending). The peaks at 798 and $621 \mathrm{~cm}^{-1}$ in the FTIR spectrum of rice husk ash, both related to the symmetrical stretching of Si-O-Si (probably cristobalite, according to the data obtained in

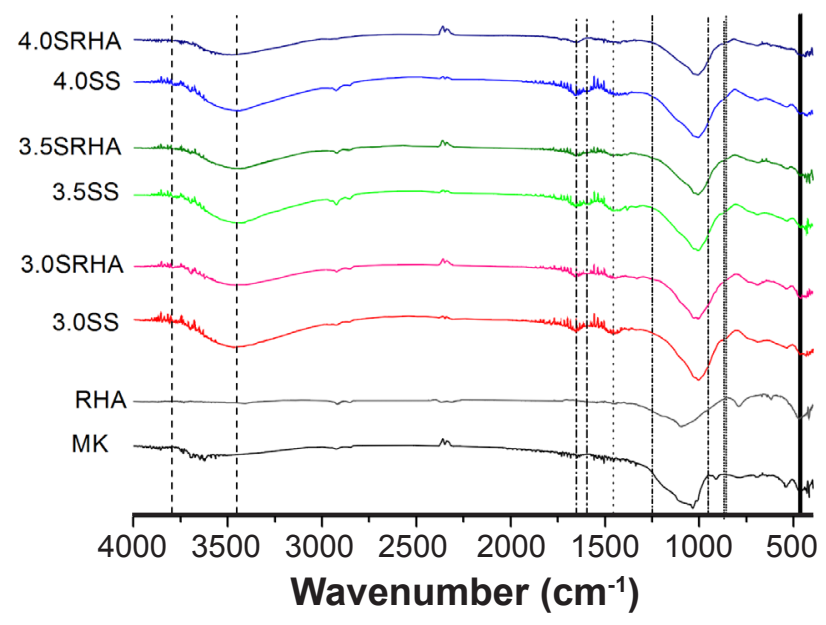

Figure 3: FTIR spectra of geopolymers, MK, and RHA. the diffraction test, Fig. 1b), were associated with the surface of the RHA solid particles [53-55].

Geopolymers: Fourier-transform infrared (FTIR) spectroscopy is well-known as a technique to characterize geopolymers. The MK bands were shifted to different values when it came into contact with the activator solution. The bands between 3800 and $3450 \mathrm{~cm}^{-1}$ were associated with the $\mathrm{O}-\mathrm{H}$ vibrations, and bands between 1650 and $1630 \mathrm{~cm}^{-1}$ were attributed to the $\mathrm{H}-\mathrm{O}-\mathrm{H}$ vibrations; they indicated the presence of weak bonds of $\mathrm{H}_{2} \mathrm{O}$ molecules, absorbed on the surface or trapped in the cavities of the geopolymeric structure $[39,53]$, indicating the presence of water in the geopolymeric structure in all samples. The band around $1460 \mathrm{~cm}^{-1}$ was attributed to the efflorescence phenomenon (formation of $\mathrm{Na}_{2} \mathrm{CO}_{3}$ ). The formation of this compound was the result of the reaction between sodium hydroxide (present in the activator solution) and carbon dioxide (present in the air) $[39,53,56]$ :

$$
\mathrm{NaOH}+\mathrm{CO}_{2} \rightarrow \mathrm{Na}_{2} \mathrm{CO}_{3}+\mathrm{H}_{2} \mathrm{O}
$$

All the geopolymers produced with SS and SRHA (3.0SS, 3.5SS, 4.0SS, 3.0SRHA, 3.5SRHA, and 4.0SRHA) presented a band around $1460 \mathrm{~cm}^{-1}$, indicating the occurrence of efflorescence in all samples. For the geopolymers produced with SS (3.0SS, 3.5SS, and 4.0SS), apparently, there was no difference between the peaks with the variation of the molar ratio $\mathrm{SiO}_{2} / \mathrm{Al}_{2} \mathrm{O}_{3}$. In the samples with SRHA (3.0SRHA, 3.5SRHA, and 4.0SRHA), this peak appeared to decrease with the increase of $\mathrm{SiO}_{2} / \mathrm{Al}_{2} \mathrm{O}_{3}$ ratio, indicating that the presence of an alternative silicate decreased the reaction between the sodium hydroxide, present in the geopolymer, with the carbon dioxide, present in the atmosphere $[39,53$, 56]. For the samples with $\mathrm{SiO}_{2} / \mathrm{Al}_{2} \mathrm{O}_{3}$ ratio of 3.5 and 4.0, there was a decrease of the peak related to the efflorescence phenomenon, near $1460 \mathrm{~cm}^{-1}$, in the samples with relation $\mathrm{SiO}_{2} / \mathrm{Al}_{2} \mathrm{O}_{3}$ molded with SRHA (3.5 SRHA and 4.0 SRHA) compared to the samples produced with SS (3.5 SS and 4.0 SS) $[39,53,56]$. The peaks found at $1035 \mathrm{~cm}^{-1}$ in MK in all samples and at $1090 \mathrm{~cm}^{-1}$ in the RHA for the samples produced with SRHA were shifted to smaller values (between 1006 and $1009 \mathrm{~cm}^{-1}$ ); these displacements may be related to the formation of the aluminosilicate gel and the formation of a three-dimensional structure involving silicon and tetrahedral aluminum, indicating a possible formation of a gel in all samples (3.0SS, 3.5SS, 4.0SS, 3.0SRHA, 3.5SRHA, and 4.0SRHA) [39, 53, 57]. These shifts occurred even for the sample 3.OSRHA, which did not obtain strength. This effect can be explained by the presence of silicates in the activator solution. The dissolved silicate species present intense vibrations in the same region attributed to the geopolymeric network, making it difficult to distinguish between these two chemical groups. In particular, the species of monomer and dimer silicates display vibrating bands in this region [58].

For the geopolymers produced with SS (3.0SS, 3.5SS, and 4.0SS), the $\mathrm{SiO}_{2} / \mathrm{Al}_{2} \mathrm{O}_{3}$ ratio did not influence the FTIR spectrum, and all geopolymers presented the same peaks 
with similar intensities. However, geopolymers produced with SRHA (3.0SRHA, 3.5SRHA, and 4.0SRHA) showed some differences between the samples, which are reported below. The peaks at 913 and $796 \mathrm{~cm}^{-1}$ in the FTIR spectrum of MK, associated with the $\mathrm{Al}-\mathrm{OH}$ bond and $\mathrm{Si}-$ O-Si symmetrical stretching, respectively, on the surface of the MK solid particles [14, 54, 55], were not found in the geopolymer samples (3.0SS, 3.5SS, 4.0SS, 3.0SRHA, 3.5SRHA, and 4.0SRHA), indicating the dissolution of these species in all samples. The peaks at 798 and $621 \mathrm{~cm}^{-1}$ in the FTIR spectrum of RHA, both related to the $\mathrm{Si}-\mathrm{O}-\mathrm{Si}$ symmetrical stretching relative to the surface of the rice husk ash solid particles [54, 55], were not found in the samples obtained with SRHA, indicating the dissolution of these species in the samples 3.0SRHA, 3.5SRHA, and 4.0SRHA. Qualitatively, it was possible to observe that the cristobalite was consumed with the increase of the $\mathrm{SiO}_{2} / \mathrm{Al}_{2} \mathrm{O}_{3}$ ratio, also observed by XRD test (Fig. 2). The appearance of a shoulder between 860 and $870 \mathrm{~cm}^{-1}$ in the samples was associated with the symmetric stretching of the Al-O, a characteristic of the geopolymeric gel dissolution [59-61]. Since this is a characteristic band of the alumina dissolution, this compound was not present in the silicates. This shoulder was not present in the sample 3.0SRHA, possibly indicating that the dissolution of the aluminum species in this particular sample did not occur. The peak reduction at $460-470 \mathrm{~cm}^{-1}$ indicated the dissolution of the species $\mathrm{Si}-\mathrm{O}-\mathrm{Si}$ and $\mathrm{O}-\mathrm{Si}-\mathrm{O}$ for the formation of the geopolymer structure bonds [25]. For the SS samples (3.0SS, 3.5SS, and 4.0SS), no change in this band was observed, while in the samples with SRHA (3.0SRHA, 3.5SRHA, and 4.0SRHA), this peak appeared to have a greater intensity for the sample with a lower $\mathrm{SiO}_{2} /$ $\mathrm{Al}_{2} \mathrm{O}_{3}$ molar ratio (3.0 SRHA).

Compressive strength: Fig. 4 shows the results of compressive strength; the specimens formulated with a $\mathrm{SiO}_{2} / \mathrm{Al}_{2} \mathrm{O}_{3}$ molar ratio of 3.0 and molded with SRHA did not present strength in the test due to the inefficient dissolution of alumina, according to the FTIR analysis (shoulder between 860 and $870 \mathrm{~cm}^{-1}$ associated to the symmetric stretching of $\mathrm{Al}-\mathrm{O}$ ). For the geopolymers produced with $\mathrm{SS}$, the best results were obtained with the sample $4.0 \mathrm{SS}$, with a compressive strength value of $3.80 \pm 0.53 \mathrm{MPa}$ for the 7 days and $4.06 \pm 0.50 \mathrm{MPa}$ for the 28 days. The best results for the SRHA were obtained with the sample 4.0SRHA, with compressive strength of $6.33 \pm 0.23$ $\mathrm{MPa}$ for the 7 days and $4.93 \pm 0.31 \mathrm{MPa}$ for the 28 days. Analyzing the average values of compressive strength, it was noticed an increase in compressive strength for all cases with the increase of the $\mathrm{SiO}_{2} / \mathrm{Al}_{2} \mathrm{O}_{3}$ molar ratio. It was observed that the compressive strength of geopolymers is related to the amorphization degree of the geopolymeric structure and that an increase of the amorphous phase results in an increment of compressive strength [62]. This was observed in the data obtained by the compressive strength test (Fig. 4) and X-ray diffraction results (Fig. 2). The highest compressive strength results were obtained

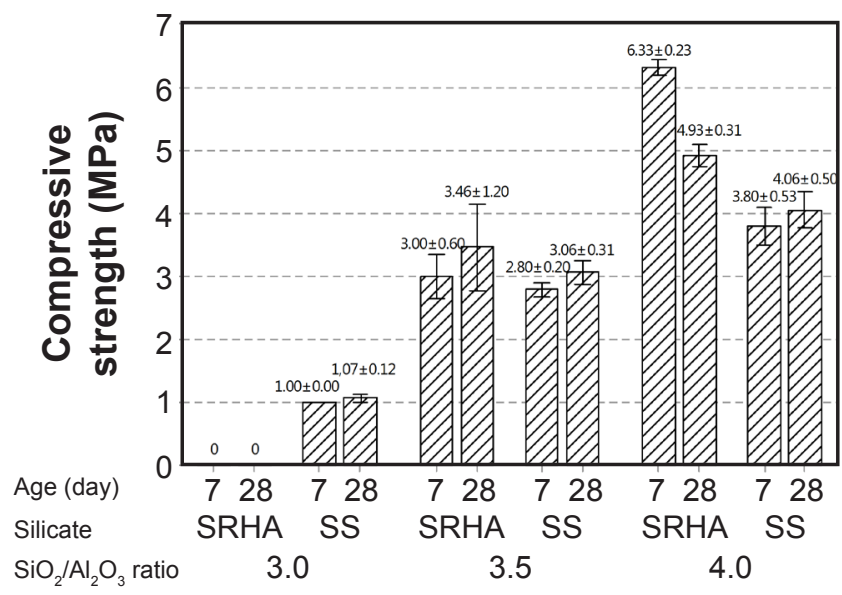

Figure 4: Compressive strength of geopolymers.

in the samples with the highest amorphization degree. Both geopolymers produced with SS and SRHA presented higher compressive strength results due to the greater $\mathrm{SiO}_{2} / \mathrm{Al}_{2} \mathrm{O}_{3}$ molar ratio. For the SS, previous studies $[1,7$, $25,36,37,52,53,63]$ have already indicated this trend. The addition of soluble silica in the activator solution can decrease the level of the structural ordering and, therefore, increase the disordering level of the system. This disorder results in an increase in compressive strength [38]. This increase in compressive strength can occur due to the fact that the $\mathrm{Si}-\mathrm{O}-\mathrm{Si}$ bond is stronger than the $\mathrm{Si}-\mathrm{O}-\mathrm{Al}$ and $\mathrm{Al}-$ $\mathrm{O}-\mathrm{Al}$ bonds and because the increase in this ratio increases the number of the species of $\mathrm{Si}-\mathrm{O}-\mathrm{Si}$ in the geopolymer structure [64].

The curing time did not significantly influence the compressive strength of the studied samples. However, the values obtained at 28 days were higher, for the most part, than those found at 7 days. Geopolymers generally do not have a significant increase in compressive strength in advanced ages since the microstructure forms quickly [27]. Only the sample 4.0SRHA presented a lower compressive strength at 28 days than at 7 days. A decrease in strength with the increase of age may occur in some cases, especially in geopolymers with high concentrations of soluble silicates. This occurs due to the low crystallinity of the gel formed during the reactions and the beginning of the crystallization of the zeolite, as a result of a certain thermodynamic instability of the amorphous reaction products [36]. Analyzing the average values of compressive strength (Fig. 4), in most samples, the geopolymers produced with SRHA showed compressive strength values higher than those obtained by the SS. This did not occur only for those samples with a $\mathrm{SiO}_{2} / \mathrm{Al}_{2} \mathrm{O}_{3}$ ratio of 3 , which did not present compressive strength. The increase in strength was attributed to the largest solid/liquid ratio used in geopolymers with SRHA due to the choice of not filtering the silicate. The effect of the solid/liquid ratio seems similar to what happens with Portland cement compounds. The increase of the solid/liquid ratio provides an increase in compressive strength of geopolymeric pastes $[6,34,65]$. 


\section{CONCLUSIONS}

Results indicated that the use of the rice husk ash (RHA) to produce sodium silicate for geopolymer reactions is not only feasible but can also result in ecofriendlier geopolymers with higher compressive strengths. For $\mathrm{SiO}_{2} / \mathrm{Al}_{2} \mathrm{O}_{3}$ molar ratio of 3.5 and 4.0 , the use of the alternative silicate promoted greater silica dissolution, maximizing the geopolymerization reaction, as well as higher mechanical performance and lower efflorescence phenomenon, which suggested a higher chemical resistance in geopolymers prepared with RHA. On the other hand, for the $\mathrm{SiO}_{2} / \mathrm{Al}_{2} \mathrm{O}_{3}$ molar ratio of 3.0 , the use of the alternative sodium silicate apparently affected the dissolution of the alumina, as well as the strength development. According to FTIR spectra, geopolymers produced with the alternative silicate presented a better dissolution of aluminum species for the 3.5 and $4.0 \mathrm{SiO}_{2} / \mathrm{Al}_{2} \mathrm{O}_{3}$ molar ratios when compared to the 3.0 ratio. Compressive strength increased with increasing $\mathrm{SiO}_{2} / \mathrm{Al}_{2} \mathrm{O}_{3}$ molar ratio for both geopolymers molded with commercial sodium silicate and alternative silicate from rice husk ash, suggesting that this parameter is not affected by the complementary source of silica. Geopolymers produced with sodium silicate from RHA showed higher compressive strengths for most studied samples. The highest compressive strength $(6.33 \pm 0.23 \mathrm{MPa})$ was obtained for a sample with $\mathrm{SiO}_{2} / \mathrm{Al}_{2} \mathrm{O}_{3}$ ratio of 4.0 at 7 days, representing a $40 \%$ increase on the average value compared to the sample prepared with commercial sodium silicate under the same conditions.

\section{REFERENCES}

[1] J. Davidovits, Geopolymer chemistry and applications, $4^{\text {th }}$ ed., Inst. Géopolym., Saint-Quentin (2015).

[2] K. Komnitsas, D. Zaharaki, Miner. Eng. 20 (2007) 1261.

[3] J.L. Provis, Mater. Struct. Constr. 47 (2014) 11.

[4] B. Majidi, Mater. Technol. 24 (2009) 79.

[5] E.A. Azimi, M. Mustafa, A. Bakri, L.Y. Ming, H.C. Yong, K. Hussin, I.H. Aziz, Rev. Adv. Mater. Sci. 44 (2016) 273.

[6] H. Cheng, K.L. Lin, R. Cui, C.L. Hwang, T.W. Cheng, Y.M. Chang, Constr. Build. Mater. 88 (2015) 74.

[7] W.K. Part, M. Ramli, C.B. Cheah, Constr. Build. Mater. 77 (2015) 370.

[8] A. Bagheri, A. Nazari, A. Hajimohammadi, J.G. Sanjayan, P. Rajeev, M. Nikzad, T. Ngo, P. Mendis, J. Clean. Prod. 189 (2018) 805.

[9] A. Palomo, M.W. Grutzeck, M.T. Blanco, Cem. Concr. Res. 29 (1999) 1323.

[10] L.K. Turner, F.G. Collins, Constr. Build. Mater. 43 (2013) 125.

[11] B. Yan, P. Duan, D. Ren, Ceram. Int. 43 (2017) 1052.

[12] A. Mellado, C. Catalán, N. Bouzón, M.V. Borrachero, J.M. Monzó, J. Payá, RSC Adv. 4 (2014) 23846.

[13] H.K. Tchakouté, C.H. Rüscher, S. Kong, E. Kamseu, C. Leonelli, J. Sol-Gel Sci. Technol. 78 (2016) 492.

[14] E. Kamseu, L.M. Beleuk à Moungam, M. Cannio, N. Billong, D. Chaysuwan, U.C. Melo, C. Leonelli, J. Clean.
Prod. 142 (2017) 3050.

[15] H.K. Tchakouté, C.H. Rüscher, S. Kong, E. Kamseu, C. Leonelli, Constr. Build. Mater. 114 (2016) 276.

[16] K.W. Kow, R. Yusoff, A.R.A. Aziz, E.C. Abdullah, J. Non. Cryst. Solids 386 (2014) 76.

[17] S.A. Bernal, E.D. Rodríguez, R. Mejia De Gutiérrez, J.L. Provis, S. Delvasto, Waste Biomass Valori. 3 (2012) 99. [18] E.D. Rodríguez, S.A. Bernal, J.L. Provis, J. Paya, J.M. Monzo, M.V. Borrachero, Cem. Concr. Compos. 35 (2013) 1. [19] R. Pode, Renew. Sustain. Energy Rev. 53 (2016) 1468.

[20] N. Bouzón, J. Payá, M.V. Borrachero, L. Soriano, M.M. Tashima, J. Monzó, Mater. Lett. 115 (2014) 72.

[21] J.M. Mejía, R. Mejía de Gutiérrez, F. Puertas, Mater. Constr. 63 (2013) 361.

[22] R.H. Geraldo, L.F.R. Fernandes, G. Camarini, J. Clean. Prod. 149 (2017) 146.

[23] H.K. Tchakouté, C.H. Rüscher, S. Kong, N. Ranjbar, J. Build. Eng. 6 (2016) 252.

[24] J.L. Provis, J.S.J. van Deventer (Eds.), "Geopolymers: structures, processing, properties and industrial applications", Woodhed Publ., Oxford (2009).

[25] A. Nazari, J.G. Sanjayan, Handbook of low carbon concrete, Elsevier (2017).

[26] J. Davidovits (Ed.), "Geopolymer, green chemistry and sustainable development solutions", Inst. Géopolym., SaintQuentin (2005).

[27] J. Davidovits, J. Therm. Anal. 35 (1989) 429.

[28] C. Tippayasam, P. Balyore, P. Thavorniti, E. Kamseu, C. Leonelli, P. Chindaprasirt, D. Chaysuwan, Constr. Build. Mater. 104 (2016) 293.

[29] Y.M. Liew, C.Y. Heah, A.B. Mohd Mustafa, H. Kamarudin, Prog. Mater. Sci. 83 (2016) 595.

[30] F. Zhang, L. Zhang, M. Liu, C. Mu, Y.N. Liang, X. Hu, Ceram. Int. 43 (2017) 3811.

[31] H. Xu, "Geopolymerisation of aluminosilicate minerals", PhD Thesis, Un. Melbourne (2002).

[32] A.D. Hounsi, G. Lecomte-Nana, G. Djétéli, P. Blanchart, D. Alowanou, P. Kpelou, K. Napo, G. Tchangbédji, M. Praisler, Ceram. Int. 40 (2014) 8953.

[33] H.Y. Leong, D.E.L. Ong, J.G. Sanjayan, A. Nazari, Constr. Build. Mater. 106 (2016) 500.

[34] N.A. Lloyd, B.V. Rangan, $2^{\text {nd }}$ Int. Conf. Sustain. Constr. Mater. Technol. 7 (2010) 1493.

[35] K.T. Nguyen, T.A. Le, J. Lee, D. Lee, K. Lee, Constr. Build. Mater. 130 (2017) 146.

[36] M.A. Longhi, E.D. Rodríguez, S.A. Bernal, J.L. Provis, A.P. Kirchheim, J. Clean. Prod. 115 (2016) 265.

[37] P. He, M. Wang, S. Fu, D. Jia, S. Yan, J. Yuan, J. Xu, P. Wang, Y. Zhou, Ceram. Int. 42 (2016) 14416.

[38] I. Ozer, S. Soyer-Uzun, Ceram. Int. 41 (2015) 10192.

[39] N. Belmokhtar, M. Ammari, J. Brigui, L. Ben Allal, Constr. Build. Mater. 146 (2017) 621.

[40] I. Lancellotti, M. Catauro, C. Ponzoni, F. Bollino, C. Leonelli, J. Solid State Chem. 200 (2013) 341.

[41] R. Siddique, Waste materials and by-products in concrete, Springer (2007).

[42] P.K. Mehta, P.J.M. Monteiro, Concrete: microstructure, 
properties, and materials, $3^{\text {rd }}$ ed., McGraw-Hill, New York (2006).

[43] M.A. Longhi, F. Gaedke, E.D. Rodríguez, A.C. Passuello, A.P. Kirchheim, in $34^{\text {th }}$ Cem. Concr. Sci. Conf. (2014) 14.

[44] Diatom, "Sodium silicate" (2018) http://diatom.com.br. [45] P. Behera, V. Baheti, J. Militky, P. Louda, Constr. Build. Mater. 163 (2018) 850.

[46] Y.J. Zhang, S. Li, Y.C. Wang, D.L. Xu, J. Non. Cryst. Solids 358 (2012) 620.

[47] M. Uysal, M.M. Al-Mashhadani, Y. Aygörmez, O. Canpolat, Constr. Build. Mater. 176 (2018) 271.

[48] Y. Wang, F. Han, J. Mu, Constr. Build. Mater. 160 (2018) 818.

[49] H.K. Tchakouté, D. Fotio, C.H. Rüscher, E. Kamseu, J.N.Y. Djobo, M.C. Bignozzi, C. Leonelli, Constr. Build. Mater. 163 (2018) 776.

[50] Z. Chen, J.S. Li, B.J. Zhan, U. Sharma, C.S. Poon, Constr. Build. Mater. 182 (2018) 597.

[51] F. Fan, Z. Liu, G. Xu, H. Peng, C.S. Cai, Constr. Build. Mater. 160 (2018) 66.

[52] P. Duxson, A. Fernández-Jiménez, J.L. Provis, G.C. Lukey, A. Palomo, J.S.J. van Deventer, J. Mater. Sci. 42 (2007) 2917

[53] C.I. Villa García, "Síntesis de geopolímeros empleando activación alcalina de aluminosilicatos minerales", Dr.
Thesis, Cent. Invest. Mater. Avanz., Mexico (2013).

[54] E.N. Kani, H. Mehdizadeh, J. Mater. Civ. Eng. 29 (2017) 4017078.

[55] W.K.W. Lee, J.S.J. van Deventer, Langmuir 19 (2003) 8726.

[56] A.G. de S. Azevedo, K. Strecker, Ceram. Int. 43 (2017) 9012.

[57] K.C. Gomes, G.S.T. Lima, S.M. Torres, S. Barros, I.F. Vasconcelos, N.P. Barbosa, Mater. Sci. Forum 643 (2010) 131. [58] C.A. Rees, J.L. Provis, G.C. Lukey, J.S.J. van Deventer, Langmuir 23 (2007) 9076.

[59] M. Zhang, M. Zhao, G. Zhang, D. Mann, K. Lumsden, M. Tao, Constr. Build. Mater. 124 (2016) 373.

[60] V.-C. Mónica Alejandra, R.E. David, M.-D. Gutiérrez Ruby, Ing. Investig. Tecnol. 16 (2015) 113.

[61] Y. Liu, C. Yan, X. Qiu, D. Li, H. Wang, A. Alshameri, J. Taiwan Inst. Chem. Eng. 59 (2016) 433.

[62] M. Ziolkowski, M. Kovtun, Constr. Build. Mater. 176 (2018) 452.

[63] D. Khale, R. Chaudhary, J. Mater. Sci. 42 (2007) 729.

[64] P. Duxson, J.L. Provis, G.C. Lukey, S.W. Mallicoat, W.M. Kriven, J.S.J. van Deventer, Colloids Surf. A Physicochem. Eng. Asp. 269 (2005) 47.

[65] R. Barnard, "Mechanical properties of fly ash/slag based geopolymer concrete with the addition of macro fibres", M.Eng. Thesis, Stellenbosch Un., South Africa (2014).

(Rec. 17/11/2019, Rev. 01/06/2020, Ac. 27/07/2020) 